\title{
Small-cell Carcinoma of the Endometrium Presenting as Cushing's Syndrome
}

\author{
HARUHIRO SATO ${ }^{1)}$, GENTA KANAI ${ }^{1)}$, HIROSHI KAJIWARA ${ }^{2)}$, JOHBU ITOH $^{2)}$ AND ROBERT YOSHIYUKI OSAMURA $^{2)}$ \\ ${ }^{1)}$ Department of Medicine, Tokai University School of Medicine, Kanagawa 259-1193, Japan \\ ${ }^{2)}$ Department of Pathology, Tokai University School of Medicine, Kanagawa 259-1193, Japan
}

\begin{abstract}
Small-cell carcinoma (SCC) of neuroendocrine type is an uncommon tumor of the endometrium. No previous report has documented Cushing's syndrome due to ectopic ACTH production by SCC of the endometrium. We describe a 56-year-old Japanese woman with SCC of the endometrium and multiple lung metastases presenting as Cushing's syndrome. The patient was referred to our hospital because of general fatigue with facial and leg edema, and multiple nodular lesions in the bilateral lungs on chest X-ray examination. A physical examination revealed that the patient had moon face, buffalo hump, and truncal obesity. Endocrinological examinations confirmed ACTH-dependent Cushing's syndrome. Thoracic computed tomography imaging showed multiple nodular lesions in the bilateral lungs. Abdominal magnetic resonance imaging suggested a malignant tumor of the uterus. The patient received a lung tumor biopsy and surgical hysterectomy. The endometrial carcinoma was histologically a SCC admixed with endometrioid adenocarcinoma. The SCC of the endometrium showed immunoreactivity for pro-opiomelanocortin, ACTH, and vimentin, but not for thyroid transcription factor-1. The lung biopsy specimen had the same features. These findings indicated that the SCC originated from the endometrium, and the ectopic ACTH-producing tumor caused Cushing's syndrome. This study provides the evidence that SCC of endometrial origin was an ectopic ACTH-producing tumor causing Cushing's syndrome.
\end{abstract}

Key words: Small-cell carcinoma, Endometrium, Ectopic ACTH production, Cushing’s syndrome

SMALL-CELL carcinoma (SCC) of the endometrium is a tumor resembling SCC of the lung, but arising in the endometrium [1]. SCCs are aggressive tumors that can occur throughout the female genital tract; the uterine cervix is the region most commonly affected, whereas endometrial involvement is rare [2].

A variable proportion of cervical SCCs exhibits evidence of neuroendocrine differentiation. Cervical SCCs can be associated with Cushing's syndrome due to ectopic ACTH production [3, 4]. However, no previous report has documented Cushing's syndrome due to ectopic ACTH production by a SCC of the endometrium. Here, we describe a case of a SCC of the endometrium causing Cushing's syndrome due to ectopic ACTH production.

Received Jul.27, 2009; Accepted Sep. 28, 2009 as K09E-212

Released online in J-STAGE as advance publication Oct. 16, 2009

Correspondence to: Haruhiro SATO, Department of Medicine, Tokai University School of Medicine, Shimokasuya 143, Isehara, Kanagawa 259-1193, Japan.

E-mail: hrhrsato@is.icc.u-tokai.ac.jp

\section{Patient and Methods}

\section{Case report}

A 56-year-old Japanese woman consulted a local clinic because of a two-month history of general fatigue with facial and leg edema. A chest X-ray showed multiple nodular lesions in the bilateral lungs, and therefore the patient was referred to our hospital. A physical examination revealed that the patient had hypertension (167/95 mmHg), facial and leg edema, and features of Cushing's syndrome such as moon face, buffalo hump, and truncal obesity. Her medical history included a right oophorectomy at the age of 20 years. Menarche had occurred at the age of 13 years, and until menopause at the age of 53 years, her menses had been regular with a 28-day cycle and a flow lasting five days. The patient was gravida 2 , para 2 .

Results of the basal endocrinological examination are summarized in Table 1. Laboratory tests performed at $0800 \mathrm{~h}$ showed a plasma ACTH level of 234 
Table 1. Basal endocrinological values

\begin{tabular}{l|cc}
\hline & $\begin{array}{c}\text { basal } \\
\text { values }\end{array}$ & $\begin{array}{c}\text { normal } \\
\text { range }\end{array}$ \\
\hline Plasma ACTH at 0800 h $(\mathrm{pg} / \mathrm{mL})$ & 234 & $7.4-55.7$ \\
Serum cortisol at 0800 h $(\mu \mathrm{g} / \mathrm{dL})$ & 54.0 & $4.0-18.3$ \\
Serum DHEAS $(\mathrm{ng} / \mathrm{mL})$ & 2730 & $80-1880$ \\
PRA $(\mathrm{ng} / \mathrm{mL} / \mathrm{h})$ & 0.7 & $0.3-5.4$ \\
Upright plasma aldosterone $(\mathrm{pg} / \mathrm{mL})$ & 68 & $39-307$ \\
Blood serotonin (ng/mL) & 60 & $57-230$ \\
TSH ( $\mu U / \mathrm{mL})$ & 0.028 & $0.30-4.00$ \\
Free T4 (ng/dL) & 0.79 & $0.75-1.75$ \\
Urinary free cortisol ( $\mu$ g/day) & 1940 & $11.2-80.3$ \\
Urinary 17-OHCS (mg/day) & 46.1 & $2.2-7.3$ \\
Urinary 17-KS (mg/day) & 35.0 & $2.4-11.0$ \\
Urinary metanephrine (mg/day) & 0.05 & $0.05-0.23$ \\
Urinary normetanephrine (mg/day) & 0.18 & $0.07-0.26$ \\
Urinary VMA (mg/day) & 4.2 & $1.3-5.1$ \\
Urinary 5-HIAA (mg/day) & 4.3 & $1.0-6.0$ \\
\hline
\end{tabular}

DHEAS, dehydroepiandrosterone sulfate; PRA, plasma renin activity; T4, thyroxine; 17-OHCS, 17-hydroxycorticosteroids; 17-KS, 17-ketosteroids; VMA, vanillylmandelic acid; 5-HIAA, 5-hydroxyindole acetic acid.

$\mathrm{pg} / \mathrm{mL}$ (normal range, 7.4-55.7), a serum cortisol level of $54.0 \mu \mathrm{g} / \mathrm{dL}$ (normal range, 4.0-18.3), a serum dehydroepiandrosterone sulfate (DHEAS) level of 2730 $\mathrm{ng} / \mathrm{mL}$ (normal range, 80-1880), plasma renin activity level of $0.7 \mathrm{ng} / \mathrm{mL} / \mathrm{h}$ (normal range, 0.3-5.4), upright plasma aldosterone level of $68 \mathrm{pg} / \mathrm{mL}$ (normal range, 39-307), blood serotonin level of $60 \mathrm{ng} / \mathrm{mL}$ (normal range, 57-230), TSH level of $0.028 \mu \mathrm{U} / \mathrm{mL}$ (normal range, 0.30-4.00), and free thyroxine (T4) level of $0.79 \mathrm{ng} / \mathrm{dL}$ (0.75-1.75). The urinary free cortisol level was $1940 \mu \mathrm{g} /$ day (normal range, 11.2-80.3). The urinary 17-hydroxycorticosteroids level was $46.1 \mathrm{mg} /$ day (normal range, 2.2-7.3). The urinary 17-ketosteroids level was $35.0 \mathrm{mg} /$ day (normal range, 2.4-11.0). Levels of urinary fractionated catecholamines were revealed as follows: urinary metanephrine $0.05 \mathrm{mg} /$ day (normal range, 0.05-0.23), urinary normetanephrine $0.18 \mathrm{mg} /$ day (normal range, 0.07-0.26), and urinary vanillylmandelic acid $4.2 \mathrm{mg} /$ day (normal range, 1.3-5.1). The urinary 5-hydroxyindole acetic acid level was $4.3 \mathrm{mg}$ /day (normal range, 1.0-6.0). These results indicated ACTH-dependent hypercortisolism. A circadian rhythm analysis showed that her serum cortisol level at $0000 \mathrm{~h}$ was $61.0 \mu \mathrm{g} / \mathrm{dL}$ (Table 2). These results suggested that the normal plasma ACTH level
Table 2. Circadian rhythms of ACTH and cortisol

\begin{tabular}{l|ccc}
\hline Clock time & $0000 \mathrm{~h}$ & $0600 \mathrm{~h}$ & $1600 \mathrm{~h}$ \\
\hline Plasma ACTH $(\mathrm{pg} / \mathrm{mL})$ & 155 & 140 & 199 \\
Serum cortisol $(\mu \mathrm{g} / \mathrm{dL})$ & 61.0 & 56.0 & 57.0 \\
\hline
\end{tabular}

Table 3. Overnight low-dose (1 mg) dexamethasone suppression test

\begin{tabular}{c|cc}
\hline & value & normal response \\
\hline Serum cortisol $(\mu \mathrm{g} / \mathrm{dL})$ & 69.2 & $<5$ \\
\hline
\end{tabular}

Table 4. Overnight high-dose (8 mg) dexamethasone suppression test

\begin{tabular}{l|cc}
\hline & value & normal response \\
\hline Serum cortisol $(\mu \mathrm{g} / \mathrm{dL})$ & 83.0 & $\begin{array}{c}<50 \% \text { of baseline in } \\
\text { Cushing’s disease }\end{array}$ \\
\hline
\end{tabular}

Table 5. CRH stimulation test

\begin{tabular}{l|cccc}
\hline & $\begin{array}{c}\text { basal } \\
\text { value }\end{array}$ & $30 \mathrm{~min}$ & $60 \mathrm{~min}$ & $120 \mathrm{~min}$ \\
\hline Plasma ACTH $(\mathrm{pg} / \mathrm{mL})$ & 151 & 154 & 147 & 142 \\
\hline
\end{tabular}

Normal response, ACTH increase $>50 \%$ over baseline value

and cortisol circadian rhythm had been lost because serum cortisol level is highest early in the morning and reaches a nadir at around midnight in normal subjects. After an overnight low-dose $(1 \mathrm{mg})$ dexamethasone suppression test, her serum cortisol level was $69.2 \mu \mathrm{g} / \mathrm{dL}$ (normal response, $<5$ ) at $0800 \mathrm{~h}$ (Table 3). After an overnight high-dose $(8 \mathrm{mg})$ dexamethasone suppression test, the serum cortisol level was $83.0 \mu \mathrm{g} /$ dL (less than $50 \%$ of baseline in Cushing's disease) at $0800 \mathrm{~h}$ (Table 4). A human CRH stimulation test (100 $\mu \mathrm{g}, \mathrm{i} . v$.$) showed that her peak ACTH level was 154$ $\mathrm{pg} / \mathrm{mL}$, suggesting no plasma ACTH response (normal response, ACTH increase $>50 \%$ over baseline value) (Table 5).

Magnetic resonance imaging (MRI) of the pituitary gland revealed no pituitary adenoma. These findings supported a diagnosis of Cushing's syndrome caused by an ectopic ACTH-producing tumor. Thoracic computed tomography (CT) imaging showed multiple nodular lesions in the bilateral lungs (Fig. 1A). Abdominal MRI suggested a malignant tumor of the uterus, and the patient was diagnosed as FIGO stage IVb. Subsequently, she was referred to the departments of thoracic surgery and gynecology for evaluation of the lung lesions and malignant tumor of the 
uterus, respectively. Video-assisted thoracoscopic surgery (VATS) to evaluate the lung lesions and hysterectomy with right salpingectomy and left salpingo-oophorectomy were performed. The uterine body contained a mass lesion, which was a solid whitish nodular mass measuring $45 \times 32 \mathrm{~mm}$, and showed endophytic growth (Fig. 1B).

The postoperative course was uneventful and the patient received chemotherapy including cisplatin and etoposide, but the levels of plasma ACTH and serum cortisol remained high. The patient was orally administered metyrapone, which inhibits $11 \beta$-hydroxylase and, consequently, her serum cortisol level decreased to the normal range. Thereafter, the physical features of Cushing's syndrome gradually ameliorated. However, the patient died of respiratory failure 3 years after hysterectomy.

\section{Immunohistochemistry}

The specimens were fixed in $10 \%$ buffered formalin, processed, and embedded in paraffin. Four- $\mu \mathrm{m}-$ thick sections were stained with hematoxylin and eosin. Antigen retrieval was performed using an autoclave (10 min at $121^{\circ} \mathrm{C}$ in $10 \mathrm{mM}$ citrate buffer). Immunohistochemical staining was performed for pro-opiomelanocortin (POMC) (mouse monoclonal 3A6, 1:50, Biogenesis, Poole, UK), prohormone convertases 1/3 (PC1/3) (rabbit polyclonal, 1:500, established in our laboratory) [5], ACTH (rabbit polyclonal, ready-to-use, DAKO, Kyoto, Japan), glucagon (rabbit polyclonal, 1:200, DAKO), insulin (rabbit polyclonal, 1:100, DAKO), calcitonin (rabbit polyclonal, 1:200, DAKO), serotonin (mouse monoclonal 5HT-H209, 1:10, DAKO), somatostatin (rabbit polyclonal, 1:300, DAKO), pancreatic polypeptide (PP) (rabbit polyclonal, 1:1000, DAKO), gastrin (rabbit polyclonal, 1:500, DAKO), gastrin-releasing peptide (rabbit polyclonal, 1:200, DAKO), erythropoietin (EPO) (goat polyclonal, N-19, 1:50, Santa Cruz Biotechnology, Inc. California, USA), parathyroid hormone (PTH) (goat polyclonal, N-18, 1:50, Santa Cruz Biotechnology Inc.), vimentin (mouse monoclonal V9, 1:100, DAKO), and thyroid transcription factor-1 (TTF-1) (mouse monoclonal SPT24, 1:100, Novocastra, Newcastle, UK).

The investigation was performed in accordance with the principles of the Declaration of Helsinki and approved by the institutional review board committee
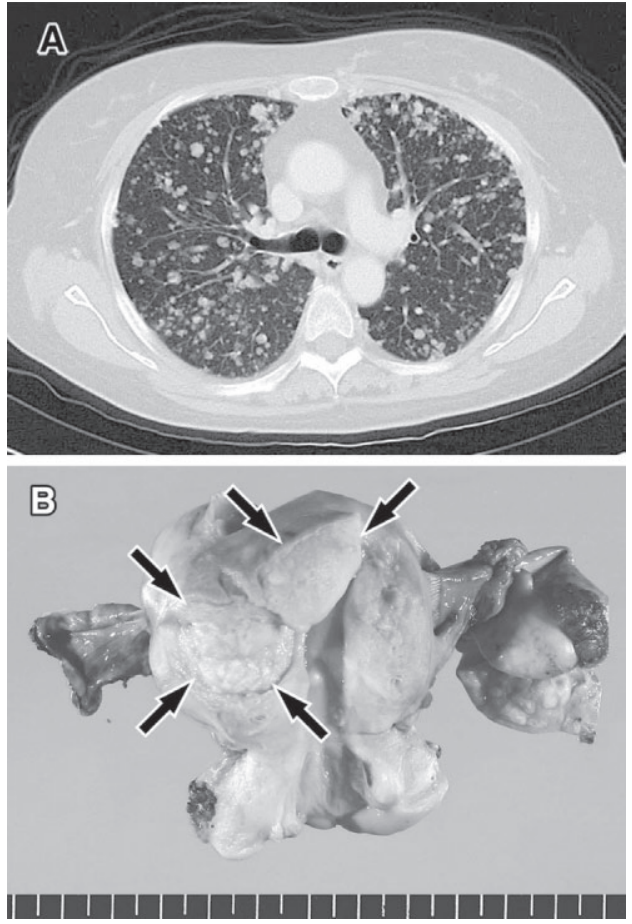

Fig. 1

A, Thoracic computed tomography image showing multiple nodular lesions in the bilateral lungs.

B, Macroscopic appearance of the surgical specimen. Arrows pointing to a solitary tumor of the endometrium measuring $45 \times$ $32 \mathrm{~mm}$.

at Tokai University School of Medicine.

\section{Results}

\section{Microscopic features}

The endometrial tumor cells were comprised of two morphological components. Most were poorly differentiated and intermediate in size, forming sheets and nests with small, round, and hyperchromatic nuclei, indistinct nucleoli, and scanty cytoplasm with a high nucleus/cytoplasm ratio (Fig. 2A). The other component was characterized by some glandular or villoglandular structures (Fig. 2B). These findings were compatible with SCC of the endometrium admixed with endometrioid adenocarcinoma. Tumor cells did not show Crooke's hyaline change.

The tumor cells in the lung possessed the same microscopic features as those in the endometrium. The crashed spindle shape of the nuclei appeared to be a 

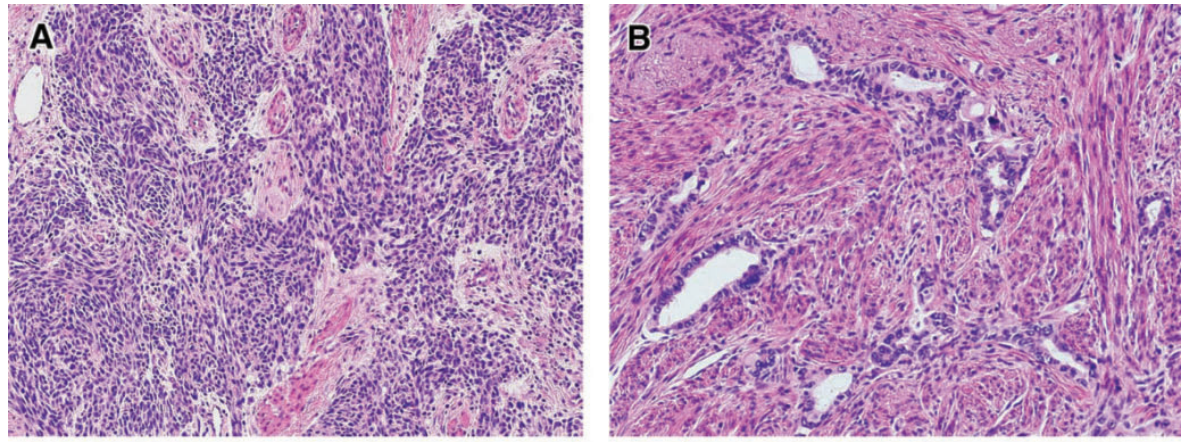

Fig. 2

A, Hematoxylin and eosin (H\&E)-stained section of the small-cell carcinoma component showing that the tumor cells are poorly differentiated, small to intermediate in size, forming sheets and nests, and containing small, round hyperchromatic nuclei with indistinct nucleoli and scanty cytoplasm; B, H\&E-stained section of the adenocarcinoma component showing that the other tumor component is an endometrioid adenocarcinoma characterized by the presence of some glandular or villoglandular structures. Original magnification $\times 40$.

VATS artifact (Fig. 5A).

\section{Immunohistochemistry}

Both the SCC and endometrioid adenocarcinoma of the endometrium were immunoreactive for POMC, PC1/3, ACTH, and glucagon (Fig. 3A-H). Immunoreactivities for insulin, calcitonin, serotonin, somatostatin, PP, gastrin, GRP, EPO, and PTH were negative in both the SCC and endometrioid adenocarcinoma of the endometrium (not shown).

Immunoreactivity for vimentin was positive in both the SCC (Fig. 4A) and endometrioid adenocarcinoma of the endometrium (Fig. 4B). Immunoreactivity for TTF-1 was negative in both the SCC (Fig. 4C) and endometrioid adenocarcinoma (Fig. 4D) of the endometrium. Both the SCC and endometrioid adenocarcinoma of the lung were immunoreactive for POMC, PC1/3, ACTH, glucagon, and vimentin (not shown).

The SCC of the lung was not immunoreactive for TTF-1; however, nuclei of the alveolar epithelial cells (internal positive control) showed immunoreactivity for TTF-1 (Fig. 5B).

\section{Discussion}

The following diagnostic criteria for SCC of the endometrium have been proposed: 1) unequivocal evidence of endometrial origin, 2) dense sheet-like growth of morphologically similar small to intermediate-sized tumor cells in standard hematoxylin and eosin-stained sections, and 3) immunohistochemical staining for one or more neuroendocrine markers [6]. Furthermore, it is possible for SCC of the endometrium to be combined with endometrioid adenocarcinoma $[1,2]$. Therefore, the present case satisfied the criteria for SCC of the endometrium admixed with endometrioid adenocarcinoma.

The lung is a common site of metastatic disease as well as a primary site for SCC. Because SCC of the endometrium can be combined with endometrioid adenocarcinoma and SCC of the lung can be combined with adenocarcinoma [7], it was clinically important in the present case to determine whether the endometrium or the lung was the primary site of the SCC.

The tumor in the endometrium was macroscopically solitary, whereas CT imaging revealed multiple tumors in the lung, suggesting that the latter were metastases. It has been reported that both SCC and endometrioid adenocarcinoma of the endometrium express vimentin $[1,8,9]$. In contrast, vimentin is expressed in adenocarcinoma of the lung, but not in SCC of the lung [10]. In the present case, the SCC components in both the endometrium and lung expressed vimentin. TTF-1 is widely used in the diagnosis of thyroid and lung carcinomas [11, 12]. In the present case, both the SCC and endometrioid adenocarcinoma components showed no TTF-1 immunoreactivity. These findings suggested that the endometrium, and not the lung, was the primary site of the SCC.

On initial physical examination, the patient showed features typical of Cushing's syndrome such as moon face, buffalo hump, and truncal obesity. Because the MRI revealed no pituitary adenoma, the overnight high-dose dexamethasone suppression test failed to 

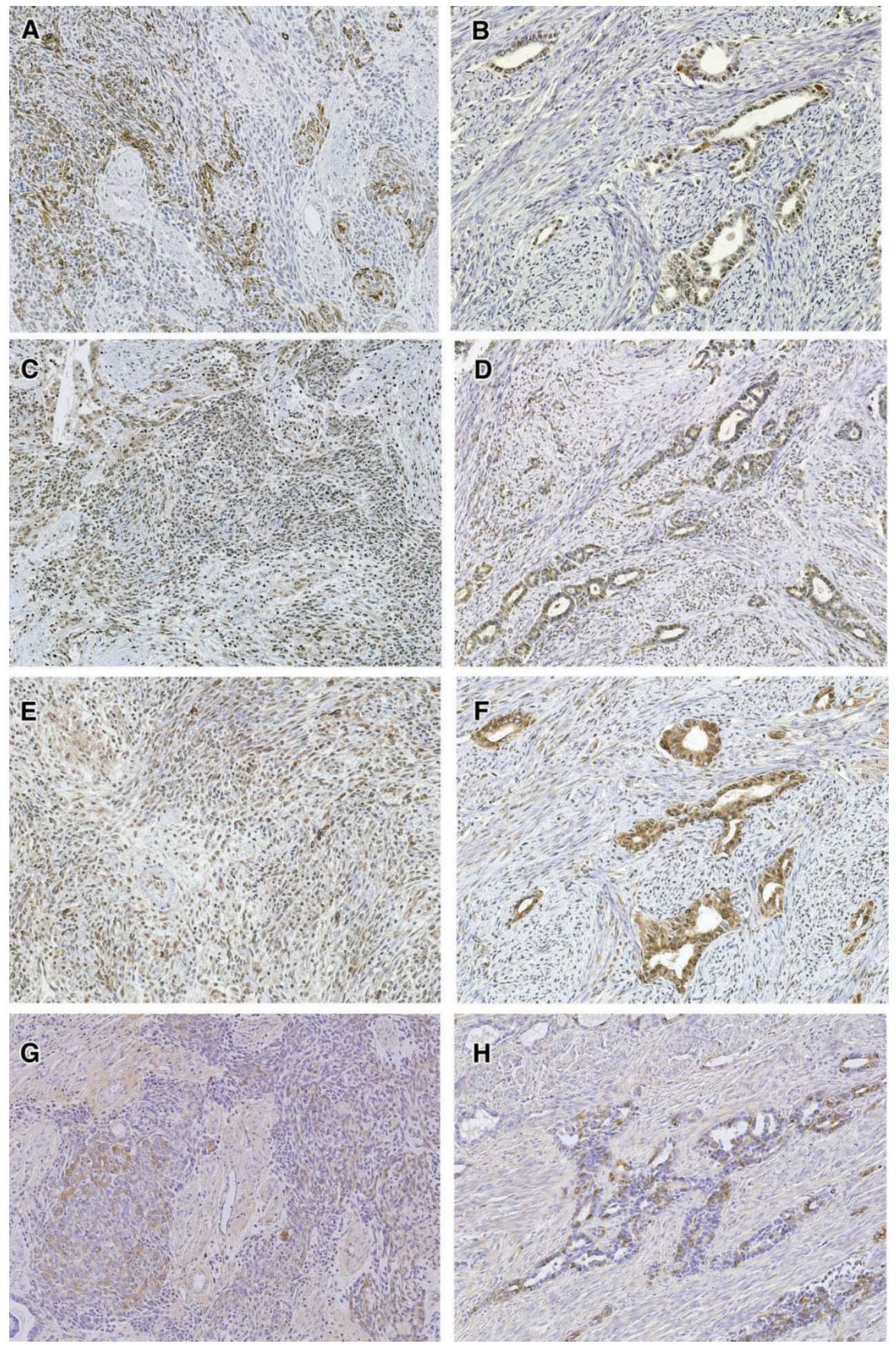

Fig. 3

Immunohistochemistry stains of the small-cell carcinoma are positive for pro-opiomelanocortin (POMC) (A), prohormone convertase 1/3 (PC 1/3) (C), ACTH (E), and glucagon (G). Immunohistochemistry stains of the adenocarcinoma component are positive for POMC (B), PC 1/3 (D), ACTH (F), and glucagon (H). Original magnification $\times 40$. 

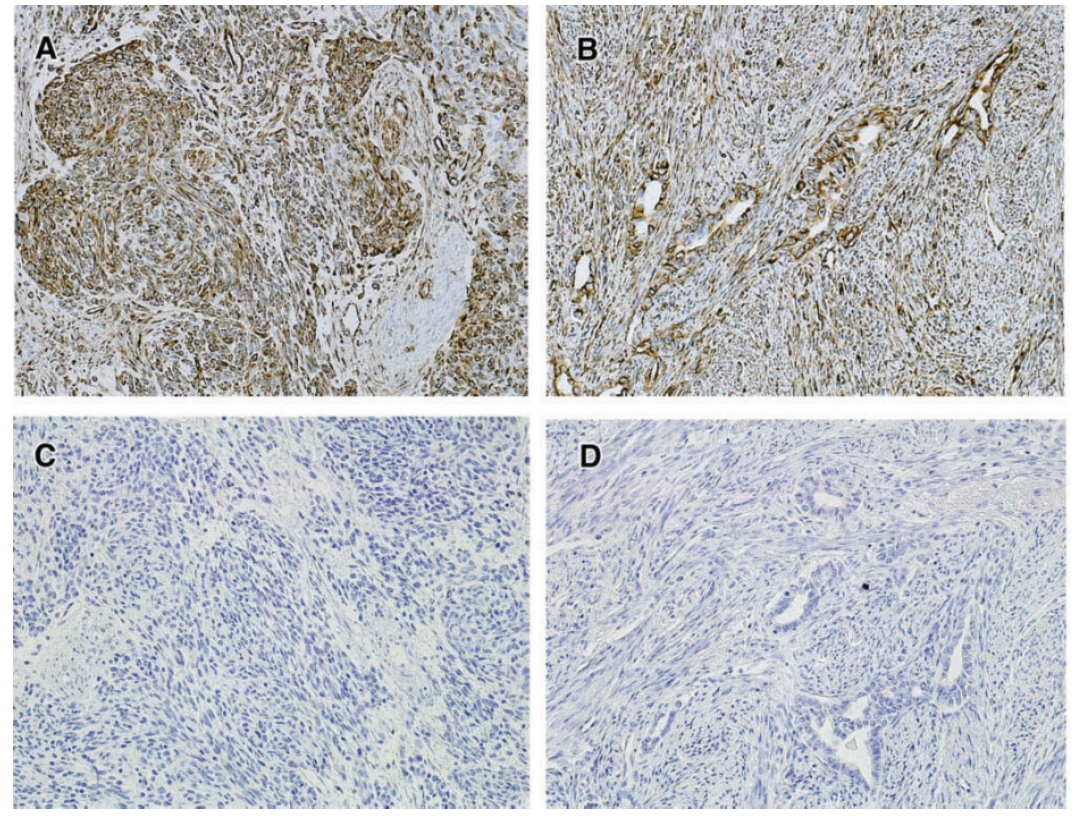

Fig. 4

Immunohistochemistry stain of vimentin was positive in both the small-cell carcinoma (A) and the adenocarcinoma component (B). But immunohistochemistry stain of thyroid transcript factor-1 was negative in both the small-cell carcinoma (C) and the adenocarcinoma component (D). Original magnification $\times 40$.

Fig. 5

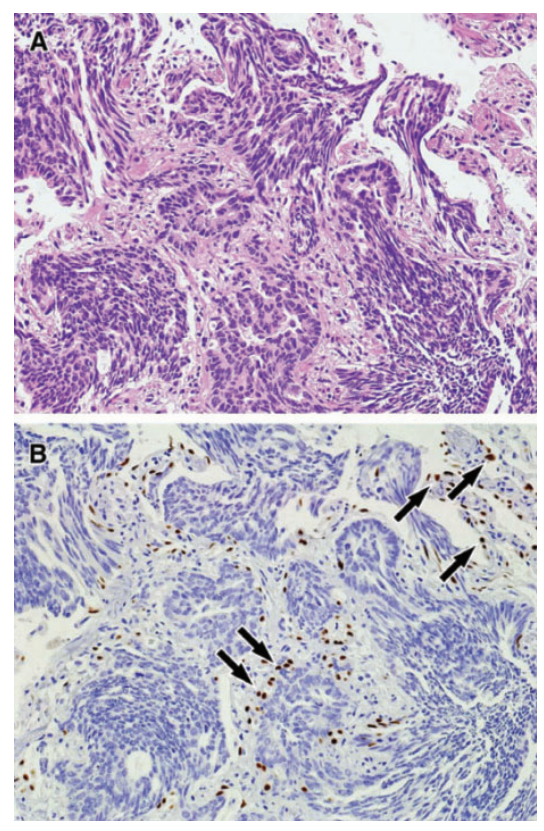

A, H\&E-stained section showing metastatic small-cell carcinoma of the lung. The crashed shape of the nuclei appears to be an artifact due to biopsy. Original magnification $\times 40$.

$B$, The small-cell carcinoma showing no immunoreactivity for thyroid transcript factor-1 (TTF-1). Nuclei of alveolar epithelial cells (internal positive control) showing immunoreactivity for TTF-1 (arrows). Original magnification $\times 40$. suppress serum cortisol and plasma ACTH did not respond to $\mathrm{CRH}$, the results were compatible with ACTH-dependent Cushing's syndrome due to an ectopic ACTH-producing tumor. The SCC of the endometrium showed immunohistochemical staining for ACTH, suggesting that it was responsible for ectopic ACTH production and causing Cushing's syndrome.

ACTH is synthesized as a precursor molecule, POMC. In the human pituitary, POMC is enzymatically processed to pro-ACTH, N-terminal POMC (N-POC), $\beta$-lipotropic hormone, ACTH (39 aminoacid residues), and $\beta$-endorphin. Processing of POMC in the pituitary takes place by PC $1 / 3$ located within mature dense core granules via the regulated secretary pathway $[13,14]$. Furthermore, it was reported that expression of PC1/3 was investigated in various endocrine tumors [15]. In contrast, it was indicated that aberrant processing of POMC might be observed in ectopic ACTH producing tumors [16]. Immunohistochemical analysis in this study revealed that immunostaining for POMC, PC1/3, and ACTH were positive in the tumor cells. These data suggested that the tumor cells produced POMC with cleavage to ACTH by PC1/3. In addition, it was suggested that ACTH produced by the tumor had biological activity 
because ACTH caused ACTH-dependent Cushing's syndrome in the patient.

The endometrioid adenocarcinoma component expressed POMC and ACTH. POMC is primarily synthesized in the pituitary gland, but its transcripts and ACTH-related peptides are detected in some tumors not associated with ectopic ACTH syndrome, and even in normal tissues as well [17-20]. Endometrioid adenocarcinoma may express ACTH [21], which would provide a possible rationale for the tumor cells of the endometrioid adenocarcinoma being responsible for ectopic ACTH production in the event of dysregulation of POMC transcription.

In conclusion, this is the first report describing a SCC of the endometrium that was responsible for ectopic production and secretion of ACTH, resulting in Cushing's syndrome. SCC of the endometrium can be one site for ectopic ACTH production when POMC transcription is dysregulated.

\section{References}

1. Silverberg SG, Mutter GL, Kurman RJ, Kubik-Huch RA, Nogales F, Tavassoli FA (2003) Epithelial tumours and related lesions. In: Tavassoli FA, Devilee P (ed) Pathology and genetics of tumours of the breast and female genital organs. IARC Press, Lyon: 221-232.

2. Huntsman DG, Clement PB, Gilks CB, Scully RE (1994) Small-cell carcinoma of the endometrium. A clinicopathological study of sixteen cases. Am J Surg Pathol 18: 364-375.

3. Hashi A, Yasumizu T, Yoda I, Kou T, Mizuno K, Hirata S, Kato J, Katoh R, Inoue M, Kawaguchi A, Nakazato M, Onaya T (1996) A case of small cell carcinoma of the uterine cervix presenting Cushing's syndrome. Gynecol Oncol 61: 427-431.

4. Shirashige Y, Watanabe T, Oki Y, Sonoda T, Adachi I (1991) A case of cervical carcinoma of the uterus presenting with hyperosmolar non-ketotic coma as a manifestation of ectopic adrenocorticotropic hormone syndrome. Jpn J Cancer Res 82: 710-715.

5. Itoh Y, Tanaka S, Takekoshi S, Itoh J, Osamura RY (1996) Prohormone convertases (PC1/3 and PC2) in rat and human pancreas and islet cell tumors: Subcellular immnohistochemical analysis. Pathol Int 46: 726-737.

6. van Hoeven KH, Hudock JA, Woodruff JM, Suhrland MJ (1995) Small cell neuroendocrine carcinoma of the endometrium. Int J Gynecol Pathol 14: 21-29.

7. Travis W, Petersen I, Nicholson S, Meyerson M, Hirsch FR, Hanash SM, Pugatch B, Jen J, Geisinger K, Takahashi T, Brambilla E, Fernandez EA, Gazdar A, Capron F (2004) Small cell carcinoma In: Travis WD, Brambilla E, Müller-Hermelink HK, Harris CC (ed) Pathology and genetics of tumours of the lung, pleura, thymus and heart. IARC Press, Lyon: 31-34.

8. Katahira A, Akahira J, Niikura H, Ito K, Moriya T, Matsuzawa S, Makinoda S, Oda T, Fujiwara K, Yaegashi N (2004) Small cell carcinoma of the endometrium: report of three cases and literature review. Int J Gynecol Cancer 14: 1018-1023.

9. Landry D, Mai KT, Senterman MK, Perkins DG, Yazdi
HM, Veinot JP, Thomas J (2003) Endometrioid adenocarcinoma of the uterus with a minimal deviation invasive pattern. Histopathology 42: 77-82.

10. Upton MP, Hirohashi S, Tome Y, Miyazawa N, Suemasu K, Shimosato Y (1986) Expression of vimentin in surgically resected adenocarcinomas and large cell carcinomas of lung. Am J Surg Pathol 10: 560-567.

11. Fabbro D, Di Loreto C, Beltrami CA, Belfiore A, Di Lauro R, Damante G (1994) Expression of thyroid-specific transcription factors TTF-1 and PAX-8 in human thyroid neoplasms. Cancer Res 54: 4744-4749.

12. Folpe AL, Gown AM, Lamps LW, Garcia R, Dail DH, Zarbo RJ, Schmidt RA (1999) Thyroid transcription factor-1: immunohistochemical evaluation in pulmonary neuroendocrine tumors. Mod Pathol 12: 5-8.

13. Benjannet S, Rondeau N, Day R, Chretien M, Seidah NG (1991) PC1 and PC2 are protein convertases capable of cleaving proopiomelanocortin at distinct pairs of basic residues. Proc Natl Acad Sci USA 88: 3564-3568.

14. Smith AI, Funder JW (1998) Proopiomelanocortin processing in the pituitary, central nervous system, and peripheral tissues. Endocr Rev 9: 159-179.

15. Scopsi L, Gullo M, Rilke F, Martin S, Steiner DF (1995) Proprotein convertases (PC1/PC3 and PC2) in normal and neoplastic human tissues: their use as markers of neuroendocrine differentiation. $J$ Clin Endocrinol Metab 80: 294-301.

16. Tsuchiya K, Minami I, Tateno T, Izumiyama H, Doi M, Nemoto T, Mae S, Kasuga T, Osamura RY, Oki Y, Hirata Y (2005) Malignant gastric carcinoid causing ectopic ACTH syndrome: discrepancy of plasma ACTH levels measured by different immunoradiometric assays. Endocr $J$ 52: 743-750.

17. Buzzetti R, McLoughlin L, Lavender PM, Clark AJ, Rees LH (1989) Expression of pro-opiomelanocortin gene and quantification of adrenocorticotropic hormone-like immunoreactivity in human normal peripheral mononuclear cells and lymphoid and myeloid malignancies. J Clin Invest 83: 733-737. 
18. DeBold CR, Menefee JK, Nicholson WE, Orth DN (1988) Proopiomelanocortin gene is expressed in many normal human tissues and in tumors not associated with ectopic adrenocorticotropin syndrome. $\mathrm{Mol}$ Endocrinol 2: 862-870.

19. Lacaze-Masmonteil T, de Keyzer Y, Luton JP, Kahn A, Bertagna X (1987) Characterization of proopiomelanocortin transcripts in human nonpituitary tissues. Proc Natl Acad Sci USA 84: 7261-7265.
20. Smith EM, Morrill AC, Meyer WJ 3rd, Blalock JE (1986) Corticotropin releasing factor induction of leukocyte-derived immunoreactive ACTH and endorphins. Nature 321: 881-882.

21. Aguirre P, Scully RE, Wolfe HJ, DeLellis RA (1984) Endometrial carcinoma with argyrophil cells: a histochemical and immunohistochemical analysis. Hum Pathol 15: 210-217. 